\title{
Discursos de posse dos Presidentes do Supremo Tribunal Federal: a tênue fronteira entre os domínios discursivos jurídico e político
}

\section{Speeches of possession of the Brazilian Presidents of the Federal Supreme Court: the fine line between the legal and political discourse areas}

Artigo

Original

\section{Claudia Maria Gil Silva ${ }^{1}$}

Original

Paper

\section{Palavras-chaves: \\ Domínio \\ Discursivo \\ Contrato de \\ Comunicação}

Ethos

\section{Resumo}

Este trabalho propõe um olhar mais cuidadoso sobre textos que trazem as marcas de um poder institucional - os discursos de posse dos Presidentes do Supremo Tribunal Federal - que, serão situados como pertencentes aos domínios discursivos jurídico e político. O binômio língua/sociedade será premissa fundamental para a realização do estudo da estrutura linguística utilizada na redação desses discursos, uma vez que o comportamento da palavra nesse espaço discursivo constrói, combinado a outros recursos, a imagem do enunciador, a qual, por sua vez, espelha a imagem do poder que representa, definindo o ethos enunciativo. O levantamento e análise das escolhas estilísticas e lexicais e da temática, dar-se-á a fim de verificarmos como se efetiva o contrato de comunicação (Charaudeau \& Maingueneau, 2006: 132). Partiremos do pressuposto teórico de esses discursos funcionarão como o lugar onde os sujeitos interagem e assumem posições sociais; onde fazem suas escolhas semânticas, ideológicas, linguísticas, lexicais, pondoas sempre a serviço do modo como organizam seu discurso.

\begin{abstract}
This paper proposes a closer look at texts that bear the marks of an institutional power - the speeches of possession by the Brazilian Presidents of the Supreme Court-which, will be located as belonging to legal and political discursive fields. The combination of language and society is important for the study of language structure used in the text of those speeches, because the behavior of the word in this discursive space constructs, combined with other sources, the image of the author, which reflects the image of power. From the survey and analysis of the stylistic and lexical choices and the theme, which underlies these texts, we will observe how the Comunication Contract works (Charaudeau \& Maingueneau, 2006: 132). We are based on a theory which defends the idea that those speeches will work as place where the subjects interact and assume social positions; where they make their semantic, ideological, linguistic and lexical choices, and use them in the way they organize their speeches.
\end{abstract}

Key words:

Discursive

domains

Communication

Contract

Ethos

\section{Conceitos Fundamentais}

Situada no centro das relações humanas está a língua. Dialógica, por princípio, constrói e desconstrói significados sociais refletindo tanto uma situação material concreta como também o con- junto das condições de vida de uma comunidade linguística. É ela o instrumento de que se utiliza o homem, por meio de enunciados orais ou escritos (Bakhtin, 2000: 279), para definir-se como pessoa entre pessoas, como aquele que pode ser reconhecido e compreendido pelos textos que produz. 
Possui recursos que, selecionados para a composição dos enunciados (estilo), adicionados à presença de um conteúdo temático (sempre adequado ao contrato de comunicação), de uma forma composicional e da função desses enunciados na comunicação compõem, como propõe Oliveira, os gêneros textuais ou gêneros discursivos, conforme Bakhtin - os quais refletem a esfera social onde são produzidos, originando, em função de propostos comunicativos, uma variedade de outros gêneros e de alguns subgêneros textuais.

A multiplicidade de gêneros existentes em uma língua se dá em função das necessidades que emergem das inovações culturais, tecnológicas, por exemplo. Podemos perceber sua manifestação nas atividades comunicativas do dia-a-dia dos usuários dessa mesma língua, pela necessidade de se comunicarem em adequação a essas inovações, uma vez que a interferência delas na comunicação pode ocorrer de forma intensa. Da mesma forma, a efemeridade de um gênero também é prevista devido à velocidade com que as mesmas inovações ocorrem.

Os gêneros textuais se relacionam, portanto, com os tipos de interação que se estabelecem no modus agendi de um determinado indivíduo ou grupo, dentro de um contexto social que pode ser ou mantido, ou desconstruído, ou reconstruído, de acordo com as necessidades desses mesmos indivíduo e grupo. Por tudo isso, trataremos os discursos de posse como "... as correias de transmissão que levam da história da sociedade à história da língua.", definição proposta por Bakhtin (2000: 285) para gênero discursivo.

Como subgênero desses discursos, situaremos os discursos de posse dos Presidentes do Supremo Tribunal Federal, pois apresentam particularidades regulares nas construções enunciativas, as quais sustentam a construção do ethos dos enunciadores e também por constituírem o lugar onde o pessoal e o oficial ocupam espaços limítrofes, ora incorporando o caráter pessoal do locutor, ora decalcando o comportamento ou "corporalidade" (Maingueneau, 2001: 55) do enunciador no espaço social em que atua, evidenciando a adesão dos sujeitos às posições discursivas que assumem, caracterizando, dessa forma, um domínio discursivo.

\subsection{Restrições e Liberdades}

A palavra, desde o momento de sua formação, quando selecionados os elementos de sua estrutura interna até a relação formal que estabelece com outras, dá ao homem a liberdade de se pôr no mundo, de selecionar parceiros, de distinguir-se como único e, ao mesmo tempo, misturar-se a tantos outros.

Nesse movimento da palavra, a relação homem / mundo / língua / sociedade se instala e desencadeia os princípios de alteridade, de influência e de regulação, os quais, como fundadores do ato de linguagem (Charaudeau, 2006: 16), acionam as relações de força que se estabelecem entre os sujeitos, marcando a assimetria de papéis presente nas relações sociais.

Palavra e poder. Esse é o binômio com o qual iniciaremos nossas considerações sobre os discursos de posse dos Presidentes do Supremo Tribunal Federal sob a perspectiva de constituírem um subgênero textual do gênero discursos de posse.

Para seja realizada a organização dos gêneros textuais, é necessário agrupá-los de acordo com os ramos da atividade humana a que pertencem, ou seja, aos domínios discursivos (Marcuschi, 2002: 23), uma vez que são nesses espaços que os gêneros e seus subgêneros se originam, agrupam, ampliam, modificam, acompanhando os movimentos sociais e históricos, os quais também renovam esses domínios.

Nessa perspectiva, enfocaremos os ramos das atividades humanas como produtores de determinadas práticas discursivas, as quais agrupam um conjunto de gêneros textuais que podem ser, às vezes, bastante específicos, como por exemplo, as práticas comunicativas pertencentes a determinadas instituições.

Fica, dessa forma, impossível dissociar a situação de comunicação dos domínios discur-

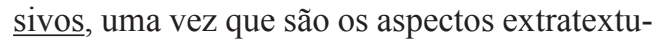
ais que os caracterizam, ou seja, as situações institucionais, históricas, sociais e ideológicas são as responsáveis pelas realizações discursivas nos textos.

A título de exemplo podemos citar os discursos jurídico e político como práticas comunicativas institucionais e, sob o ponto de vista dos domínios discursivos, afirmar que esses discursos constituem, cada um, um domínio diverso capaz de abrigar diferentes gêneros e 
subgêneros textuais, os quais são organizados em modos que visam a uma função específica na comunicação - "a função do narrativo é contar ou relatar; a do descritivo, descrever; a do argumentativo, argumentar, (...)" (Oliveira, 2003: 41) -, caracterizam-se pelas realizações linguísticas definidas por propriedades sóciocomunicativas, situam-se dentro de uma prática comunicativa, na qual exercem um papel social, respeitam as restrições e reconhecem as liberdades ligadas a um ato de linguagem, isto é, são regidos por um contrato de comunicação.

\section{Os discursos de posse dos} Presidentes do Supremo Tribunal Federal: Um Subgênero Textual

Como um subgênero dos discursos de posse, situaremos os dos Presidentes do Supremo Tribunal Federal, uma vez que apresentam particularidades regulares em suas construções enunciativas, as quais sustentam a construção do ethos dos enunciadores e do poder que representam.

Para este estudo, fizemos um recorte temporal, concentrando o corpus de análise em discursos associados a uma memória, a um contexto histórico, social, político, impregnados de uma carga semântica que marca a imagem de um Brasil que pode ser reconhecido no trinômio "Vida - Morte - Vida", uma imagem contida na temporalidade "Brasil, capital Brasília". Selecionamos fragmentos de dois discursos de posse de Presidentes do Supremo Tribunal Federal: o do Ministro Antônio Carlos Lafayette de Andrada - primeiro presidente eleito e empossado em Brasília - e da Ministra Ellen Gracie - atual Presidente do Supremo Tribunal Federal e primeira mulher a ocupar esse cargo.

\section{A construção do ethos: "O Escolhido" Fragmentos do discurso de agradecimento do Presidente, Ministro Lafayette Andrada como Presidente do Supremo Tribunal Federal}

"Senhores Ministros:
Quero, de início, renovar agradecimentos pela
honra insigne a mim conferida por Vossas
Excelências, alçando-me ao mais elevado pos-
to do Poder Judiciário do País. (...)"

$\mathrm{O}$ enunciador inaugura seu discurso dirigindo-se exclusivamente a seus pares e dá a eles o crédito e a total responsabilidade pela sua condução à Presidência do Supremo Tribunal Federal. Agradece por ter sido o escolhido entre tantos outros, para, a seguir, ele mesmo justificar a escolha: ele é o vocacionado, o que não se arrepende, o que não muda sua crença, o que sabe a grandeza e a nobreza da "missão", o que tem fé inabalável na supremacia do direito. Dentro desse quadro de interação, o "eu” implícito nas construções verbais, marca da pessoa restrita, auxilia o enunciador tanto na justificativa de sua escolha para o cargo, inscrevendo o ethos do escolhido, quanto no propósito de garantir a imagem de um enunciador fiel a seus princípios, pois reafirma os seus ideais, de sempre, que vão ao encontro dos ideais de Justiça, os quais teriam sido, até o momento da enunciação, o fio condutor de sua vida profissional, como também responsáveis pela posição que ora ocupa no contexto jurídico nacional.

\section{Fragmentos do discurso de Posse da Ministra Ellen Gracie como Presidente do Supremo Tribunal Federal}

“O apoio que essa presença significa refor-
ça minha disposição de bem desempenhar a
honrosa tarefa de que me incumbiram meus
pares. Digo, com Guimarães Rosa, que "sua
alta opinião compõe minha valia."

$\mathrm{O}$ enunciador dirige-se exclusivamente a seus pares para agradecer a sua ascensão à Presidência daquele Poder. Traz para si a responsabilidade de ser, daquele momento em diante, a voz do Poder que assume, uma voz compartilhada com aqueles que o incumbiram de "honrosa tarefa", aqueles que o escolheram, uma voz anunciada e já compartilhada antes: "Digo, com Guimarães Rosa, que 'sua alta opinião compõe minha valia". A marca da intertextualidade em seu discurso inscreve uma voz independente, a voz autorizada de Rosa - pois ela diz com Rosa e não como Rosa -, a voz de um Brasil reconhecido num universo que vai além do Brasil, um Brasil diplomático, literário e regional. 
A situação de comunicação "posses presidenciais" exige do presidente empossado uma palavra àqueles que o elegeram. É, portanto, uma situação que se relaciona, de um modo geral, ao domínio discursivo político.

Nas posses dos Presidentes do Supremo tribunal Federal, a palavra proferida nos discursos é essencialmente política e a instância na qual ela se realiza também o é uma vez que esses Presidentes chegaram ao poder pela vontade de seus pares que, nessa circunstância não se encontra em contradição, pois conhecem as regras de funcionamento do Estado e reconhecem as condições de realização da ação política.

Já na posse do Presidente da República de um país, por exemplo, mesmo tendo chegado ao poder de forma democrática, ou seja, pela vontade cidadã, essa mesma vontade não conhece o funcionamento dos negócios do Estado, nem as condições de realização da ação política, o que coloca essa instância em contradição (Charaudeau, 2006: 18).

A presença dos discursos de posse dos Presidentes do Supremo Tribunal Federal no domínio discursivo jurídico se dá pelo fato de esses discursos apresentarem características que permeiam o discurso jurídico legal.

A variante padrão do Português do Brasil é eleita como a representação do ideal linguístico da comunidade jurídica. Pressupõe-se, portanto, que todo texto jurídico observe as conexões internas e externas da tessitura textual e que os elementos linguísticos utilizados e seus efeitos de sentido tenham sido minuciosamente selecionados pelos produtores desses textos, uma vez que as práticas discursivas constroem a imagem dos enunciadores e esses refletem a imagem do Poder que representam, usando a linguagem como instrumento de poder, que marca as diferenças, que promove a manipulação de cidadãos que não a dominam.

À conta disso, vislumbrando a relação linguística entre pessoas de polos idênticos, já que os coenunciadores nos discursos de posse dos Presidentes do Supremo Tribunal Federal são, da mesma forma que o Presidente empossado, magistrados, o domínio da palavra é fundamental para conferir credibilidade a seu discursos e para ratificar o merecimento pela conquista do poder.

\subsection{O Contrato de Comunicação}

“Cada gênero textual está associado a um contrato de comunicação, ou seja, a um conjunto de "direitos" e "deveres" de quem produz o texto e de quem o interpreta." (Oliveira, 2005), cada característica de um gênero corresponde a uma cláusula.

Presentes nos discursos de posse, de um modo geral, como também no dos Presidentes do Supremo Tribunal Federal, os vocativos.

Ora obedecendo a um protocolo hierárquico na escala dos valores sociais, ora espelhando uma das imagens que o próprio Poder faz de si ao dirigir-se unicamente a seus pares, os vocativos funcionam como uma cláusula contratual nesses gênero e subgênero textuais.

Fragmentos do discurso de Posse da Ministra Ellen Gracie como Presidente do Supremo Tribunal Federal

"Senhor Presidente da República, Luiz Inácio Lula da Silva, Senhor Presidente do Congresso Nacional, Senador Renan Calheiros, Senhor Presidente da Câmara dos Deputados, Dep. Aldo Rebelo, Senhor Procurador-Geral da República, Dr. Antônio Fernando de Barros e Silva de Souza, Senhores Ministros do Supremo Tribunal Federal, Senhores Ministros Aposentados do Supremo Tribunal Federal, Senhoras e Senhores Governadores de Estado,Senhoras e Senhores Parlamentares, Senhoras e Senhores Embaixadores, Senhores Presidentes dos Tribunais Superiores, Senhores e Senhoras Conselheiros do Conselho Nacional de Justiça, Senhoras e Senhores Presidentes e representantes dos Tribunais de Justiça, Regionais Federais e do Trabalho, Senhor Presidente do Conselho Federal da Ordem dos Advogados do Brasil, Dr. Roberto Busatto, Senhoras e Senhores magistrados, procuradores e advogados, Servidores do Supremo Tribunal Federal, Meus familiares. Meus amigos e amigas, tantos amigos, cujo comparecimento me traz grande alegria, e que tornam insuficientes as dependências deste Plenário, ..." 
Fragmentos do discurso de agradecimento do Presidente, Ministro

Lafayette Andrada como Presidente do Supremo Tribunal Federal

\section{"Senhores Ministros:}

Quero, de início, renovar agradecimentos pela honra insigne a mim conferida por Vossas Excelências, alçando-me ao mais elevado posto do Poder Judiciário do País. (...) Meus Senhores:

Escolhi a magistratura por vocação. (...)”

Reiterar o compromisso assumido (em campanha) é outra característica dos discursos de posse presente também nos discursos dos Presidentes do STF, apesar de que no âmbito do STF as campanhas presidenciais se darem de forma silenciosa e os compromissos se manifestarem de forma tácita.

\section{Fragmentos do discurso de Posse da} Ministra Ellen Gracie como Presidente do Supremo Tribunal Federal

“A meus colegas reitero a disposição de ser a porta-voz deste plenário e executora de suas decisões. Nada farei que não resulte da deliberação da maioria cujas prioridades serão também as minhas."

O enunciador traz para si a responsabilidade de ser a porta-voz do Poder que assume, um compromisso reiterado, contratado muito antes, tacitamente, quando assumiu a cadeira de Ministro da Casa.

\section{Conclusão}

O eu, o outro, o onde. A palavra, a seleção vocabular, o léxico, os sentidos.

A palavra existe para... o texto existe para... Ambos existem porque neles habita uma carga ideológica de natureza social que transita em toda e qualquer comunicação, por isso, existem para...

Compreendermos que a palavra transita num universo discursivo, cuja finalidade é constituir sentidos é necessário para que nos vejamos dentro de um ato de linguagem e possamos produzir discursos impregnados de uma carga semântica capaz de os entrelaçar a outros discursos e enunciadores, em tempos vários

Compreendemos, também, que explorar os estudos da linguagem no plano do discurso é fundamental para confirmarmos as noções de gênero e o que pode ser considerado adequado ou inadequado nos diferentes gêneros textuais; estabelecermos critérios capazes de relacionar os discursos como um determinado gênero textual; identificarmos as ideologias discursivas presentes nesses discursos para relacionálos a um domínio discursivo.

Nesse plano de estudo, também é possível observar como se dá o contrato de comunicação nos diferentes domínios discursivos e que no gênero textual discurso de posse e do subgênero discursos de posse dos Presidentes do Supremo Tribunal Federal, que analisamos, percebemos o quão tênue a linha que os separa e diferencia.

“(...) o sujeito mostra-se com sua identidade social de locutor; é ela que lhe dá direito à palavra e que funda sua legitimidade de ser comunicante em função do estatuto e do papel que são atribuídos pela situação de comunicação. (...) o sujeito constrói para si uma figura daquele que enuncia, uma identidade discursiva de enunciador que se atém aos papéis que ele se atribui em seu ato de enunciação que se impõe a ele e das estratégias que ele escolhe seguir. O sujeito aparece, portanto, ao olhar do outro, com uma identidade psicológica e social que lhe é atribuída, e, ao mesmo tempo, mostra-se mediante a identidade discursiva que ele constrói para si." Charaudeau (2006: 115)

\section{Referências Bibliográficas}

BAKHTIN, Mikhail Mikhailovitch. Estética da criação verbal. [tradução feita a partir do francês por Maria Ermantina Galvão; revisão da tradução Marina Appenzeller]. 3 ed. São Paulo: Martins Fontes, 2000.

CHARAUDEAU,Patrick\&MAINGUENEAU, Dominique. Dicionário de análise do discurso. Coordenação da tradução Fabiana Komesu. 2. ed. - São Paulo: Contexto, 2006. 
Trad. De Fabiana Komesu e Dílson Ferreira da Cruz. São Paulo: Contexto, 2006.

HENRIQUES, Claudio Cesar e Simões, Darcília Marindir P. (orgs.) A Redação de Trabalhos Acadêmicos: teoria e prática. Rio de Janeiro: EdUERJ, 2002.

KOCH, Ingedore Villaça e Elias, Vanda Maria Ler e compreender: os sentidos do texto. São Paulo: Contexto, 2006.

MAINGUENEAU, Dominique. Análises de textos de comunicação. Trad. Cecília P. de Souza-e-Silva, Décio Rocha. São Paulo: Cortez: 2001, p. 55.

MARCUSCHI, Luiz Antônio. Gêneros textuais: definição e funcionalidade.”. In: DIONISIO, Angela Paiva, MACHADO, Rachel, BEZERRA, Maria Auxiliadora. Org. Gêneros textuais \& ensino. Rio de Janeiro: Lucerna, 2002, p. 19-33.

OLIVEIRA, Ieda de. O contrato de comunicação da literatura infantil e juvenil. Rio de Janeiro: Lucerna, 2003.

OLIVEIRA, Helênio Fonseca de. Gêneros textuais e conceitos afins: questões teóricas. UNIVERSIDADE DO ESTADO DO RIO DE JANEIRO. VII Fórum de Língua Portuguesa. Rio de Janeiro: 2005.

VAL, Maria da Graça Costa. Redação e Textualidade. 2

Endereço para Correspondência:

Claudia Maria Gil Silva

Coordenadora e Professora do Curso de Letras UniFOA - Centro Universitário de Volta Redonda claudia.silva@foa.org.br

Rua Almirante Barroso, 70, apt ${ }^{\circ} 302$

Jardim Amália I - Volta Redonda

CEP: 27.251-085

Informações bibliográficas:

Conforme a NBR 6023:2002 da Associação Brasileira de Normas Técnicas (ABNT), este texto científico publicado em periódico eletrônico deve ser citado da seguinte forma SILVA, Claudia Maria Gil. Discursos de posse dos Presidentes do Supremo Tribunal Federal: a tênue fronteira entre os domínios discursivos jurídico e político. Caderno UniFOA. Volta Redonda, ano IV, n. 11, dezembro 2009. Disponível em: <http://www.unifoa.edu.br/cadernos/edicao/11/47.pdf $>$ 